\title{
The catecholate siderophores of Azotobacter vinelandif: their affinity for iron and role in oxygen stress management
}

\author{
Anthony S. Cornish and William J. Page \\ Author for correspondence: William J. Page. Tel: +1 4034924782 . Fax: +1 4034922216. \\ e-mail: bill.page@ualberta.ca
}

Department of Biological Sciences, University of Alberta, Edmonton, Alberta, Canada T6G 2E9

\begin{abstract}
In iron-limited medium, Azotobacter vinelandif strain UW produces three catecholate siderophores: the tricatecholate protochelin, the dicatecholate azotochelin and the monocatecholate aminochelin. Each siderophore was found to bind $\mathrm{Fe}^{3+}$ preferentially to $\mathrm{Fe}^{2+}$, in a ligand:Fe ratio of $1: 1,3: 2$ and 3:1, respectively. Protochelin had the highest affinity for $\mathrm{Fe}^{3+}$, with a calculated proton-independent solubility coefficient of $10^{43-9}$, comparable to ferrioxamine B. Iron-limited wild-type strain UW grown under $\mathbf{N}_{2}$-fixing or nitrogen-sufficient conditions hyper-produced catecholate siderophores in response to oxidative stress caused by high aeration. In addition, superoxide dismutase activity was greatly diminished in iron-limited cells, whereas catalase activity was maintained. The ferredoxin I (Fdl)-negative A. vinelandii strain LM100 also hyper-produced catecholates, especially protochelin, under oxidative stress conditions, but had decreased activities of both superoxide dismutase and catalase, and was about 10 times more sensitive to paraquat than strain UW. Protochelin and azotochelin held Fe ${ }^{3+}$ firmly enough to prevent its reduction by $\mathrm{O}_{2}^{-}$and did not promote the generation of hydroxyl radical by the Fenton reaction. Ferric-aminochelin was unable to resist reduction by $\cdot \mathrm{O}_{2}^{-}$ and was a Fenton catalyst. These data suggest that under iron-limited conditions, A. vinelandii suffers oxidative stress caused by $\cdot \mathrm{O}_{2}^{-}$. The catecholate siderophores azotochelin, and especially protochelin, are hyper-produced to offer chemical protection from oxidative damage catalysed by $\cdot \mathrm{O}_{2}^{-}$and $\mathrm{Fe}^{3+}$. The results are also consistent with Fdl being required for oxidative stress management in A. vinelandii.
\end{abstract}

Keywords: Azotobacter vinelandii, siderophore, iron affinity, oxygen stress

\section{INTRODUCTION}

Iron in aerobic, neutral-pH environments has very low solubility, in the order of $10^{-17} \mathrm{M}$, with most iron present as insoluble hydroxides and oxyhydroxides. This is far below the minimal concentration required for the optimal growth of micro-organisms and necessitates the production of iron chelators called siderophores which promote high-affinity iron transport (Guerinot, 1994). We have been studying the growth and survival of the obligately aerobic, Gram-negative soil organism

Abbreviations: 2,3-DHBA, 2,3-dihydroxybenzoic acid; Fdl, ferredoxin I; SOD, superoxide dismutase; Fe-SOD, iron-dependent SOD; Mn-SOD, manganese-dependent SOD.
Azotobacter vinelandii under various stress conditions. A. vinelandii produces three catecholate siderophores under iron-limited conditions: azotochelin (Corbin \& Bulen, 1969), aminochelin (Page \& von Tigerstrom, 1988) and protochelin (Cornish \& Page, 1995) (Fig. 1). Protochelin is formed from equimolar amounts of azotochelin and aminochelin; for unknown reasons, only very small quantities of protochelin are normally observed unless millimolar molybdate also is present in the growth medium (Cornish \& Page, 1995). These catecholate siderophores are potentially excellent iron chelators at neutral $\mathrm{pH}$ (Hider, 1984).

A. vinelandii also has the ability to fix $\mathrm{N}_{2}$ to survive in nitrogen-limited environments. The nitrogenases formed may have either $\mathrm{Fe}-\mathrm{Mo}, \mathrm{Fe}-\mathrm{V}$, or Fe-only active 
<smiles>O=C(NCCCCC(NC(=O)c1cccc(O)c1O)C(=O)O)c1cccc(O)c1O</smiles>

[A]<smiles>NCCCCNC(=O)c1cccc(O)c1O</smiles>

[B]

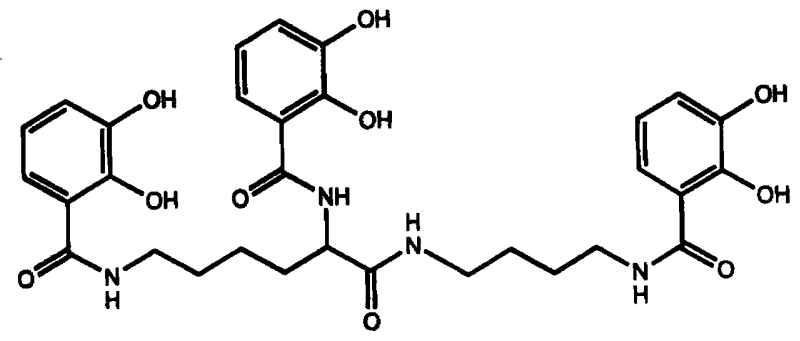

[C]

Fig. 1. Catecholate siderophores produced by $A$. vinelandii: $[A]$ azotochelin, $[B]$ aminochelin, $[C]$ protochelin (Cornish \& Page, 1995).

centres and are very sensitive to inactivation by $\mathrm{O}_{2}$ (Bishop, 1993). To protect the nitrogenase under aerobic conditions, A. vinelandii has a branched cytochrome chain with high-affinity terminal oxidases that 'waste' $\mathrm{O}_{2}$ by the formation of water without ATP synthesis (respiratory protection; Kolonay et al., 1994). This gives $A$. vinelandii the highest repiratory rate of any known organism (Jurtshuk \& Yang, 1980). Unfortunately, this respiratory activity also forms superoxide radical $\left(\cdot \mathrm{O}_{2}^{-}\right)$ and $\mathrm{H}_{2} \mathrm{O}_{2}$. Furthermore, hydroxyl radicals $(\cdot \mathrm{OH})$ may form spontaneously in the Fenton reaction by the interaction of $\mathrm{H}_{2} \mathrm{O}_{2}$ and $\mathrm{Fe}^{2+}$, which is formed by the reduction of $\mathrm{Fe}^{3+}$ in the presence of $\cdot \mathrm{O}_{2}^{-}$(Cohen, 1994).

These toxic oxygen species can cause mutagenic events, membrane peroxidation and the disintegration of ribosomes, and in general lead to cellular damage collectively referred to as oxidative stress (DiGuiseppi \& Fridovich, 1984). The response to oxidative stress is most dramatic when facultative anaerobes, like Escherichia coli, make the transition from anaerobic to aerobic environments. Under these conditions, E. coli induces the oxyR regulon in response to $\mathrm{H}_{2} \mathrm{O}_{2}$ and the soxRS regulon in response to $\cdot \mathrm{O}_{2}^{-}$(Demple, 1996). It remains an open question whether oxidative stress management exists in an obligate aerobe like $A$. vinelandii. However, it is likely that as oxygen availability in the soil fluctuates, $\mathrm{N}_{2}$ fixing growth would increase the demand for protection from toxic $\mathrm{O}_{2}$ products, and the limited availability of iron in aerobic soil would decrease the cell's ability to provide respiratory protection and active catalase or iron superoxide dismutase (SOD) enzymes. It also has been proposed that ferredoxin I (FdI) may be part of a SoxRS-like system in A. vinelandii (Isas et al., 1995). In addition, siderophores have been shown to decrease oxidative stress in the aerobe Pseudomonas aeruginosa by preventing the formation of $\cdot \mathrm{OH}$ by chelating and thus removing soluble $\mathrm{Fe}^{3+}$ from the Fenton reaction (Coffman et al., 1990). This activity is dependent on the affinity that the siderophore has for $\mathrm{Fe}^{3+}$ and hence the ability of the complex to resist reduction by $\cdot \mathrm{O}_{2}^{-}$. Thus, it was the purpose of this study to observe the interplay of iron limitation and oxidative stress management in wild-type and an isogenic FdI-negative strain of $A$. vinelandii.

\section{METHODS}

Bacterial strains and growth conditions. The strains used in this work were wild-type Azotobacter vinelandii UW (OP, ATCC 13705) and the isogenic FdI-negative ( $f d x A)$ mutant strain LM100 (Morgan et al., 1988). The basal medium used for all studies was Burk's medium (Cornish \& Page, 1995). This medium was made nitrogen-sufficient by the addition of $15 \mathrm{mM}$ ammonium acetate, while nitrogen-free medium contained $15 \mathrm{mM}$ sodium acetate. Iron-sufficient medium contained 20-75 $\mu \mathrm{M}$ ferric citrate; iron-limited medium contained $1 \mu \mathrm{M}$ ferric citrate and all glassware was acid-washed. Strains were maintained on slants of Burk's medium and liquid cultures were inoculated and incubated at $28^{\circ} \mathrm{C}$ with shaking at 225 r.p.m.

Growth and siderophore production under conditions of oxygen stress. Progressively smaller volumes of medium were incubated with shaking (225 r.p.m.) in $500 \mathrm{ml}$ Erlenmeyer flasks to increase the aeration of the cultures. In some experiments, paraquat $\left(1,1^{\prime}\right.$-dimethyl-4,4'-bipyridinium dichloride) was added at concentrations of $0 \cdot 25-30 \mu \mathrm{M}$ to increase oxidative stress (Korbashi et al., 1986).

The cells were removed from the growth medium by centrifugation and total cellular protein was determined by the Lowry method. Siderophores were detected either by the colorimetric assay of Barnum (1977) or by measuring the $A_{310}$ of acidified ( $\mathrm{pH} 1.8$ with $12 \mathrm{M} \mathrm{HCl}$ ) culture supernatant fluid using a Hitachi U-2000 recording spectrophotometer. Catecholate siderophore concentrations in stock solutions were quantified by using the absorption coefficient for 2,3dihydroxybenzoic acid (2,3-DHBA) in $80 \%$ methanol of $3.2629 \times 10^{-3} A_{310} \mathrm{~cm}^{-1} \mu \mathrm{M}^{-1}$, or in buffer of $3.2455 \times 10^{-3} A_{310}$ $\mathrm{cm}^{-1} \mu \mathrm{M}^{-1}$, corrected for the number of 2,3-DHBA moieties per siderophore. Azotobactin in acidified culture supernatant fluid was quantified by measuring $A_{380}$ (Page $\&$ Huyer, 1984).

Production and identification of siderophores. Culture supernatant fluid of strain LM100 was used as a source of all catecholate siderophores, as protochelin was formed without the addition of $1 \mathrm{mM}$ molybdate. Iron-limited medium (400 ml in a 2 litre flask) was inoculated with iron-limited strain LM100 (4\%, v/v) and after $24 \mathrm{~h}$ incubation cells were removed by tangential-flow filtration using dual $0.22 \mu \mathrm{m}$ pore size Pellicon (Millipore) filters. The culture fluid volume (9.6 litres) was reduced to $400 \mathrm{ml}$ under vacuum in the dark at $37^{\circ} \mathrm{C}$ using a Buchi RE111 rotary evaporator.

Siderophores were isolated according to the following protocol. The culture fluid was acidified to $\mathrm{pH} 1.8$ with $12 \mathrm{M} \mathrm{HCl}$ and extracted twice with an equal volume of ethyl acetate to 
concentrate azotochelin, protochelin and 2,3-DHBA (Cornish $\&$ Page, 1995). The remaining acidic aqueous layer contained aminochelin (Page \& von Tigerstrom, 1988) and was neutralized to $\mathrm{pH} 7.0$ with $12 \mathrm{M} \mathrm{NaOH}$, reduced in volume to $50 \mathrm{ml}$ and extracted five times with an equal volume of butanol. This extract was then evaporated to dryness and the resulting residue was dissolved in $5 \mathrm{mM}$ ammonium acetate $(\mathrm{pH} 7 \cdot 0)$ for application to a $2.5 \mathrm{~cm} \times 30 \mathrm{~cm}$ CM-Sephadex (Pharmacia) column equilibrated in $5 \mathrm{mM}$ ammonium acetate ( $\mathrm{pH} \mathrm{7.0)}$. Fractions $(5 \mathrm{ml})$ were eluted with a $400 \mathrm{ml}$ gradient of 5-2000 mM ammonium acetate ( $\mathrm{pH} 7 \cdot 0$ ) and $A_{310}$ was used to detect catecholates. Fractions containing aminochelin were confirmed with TLC by comparison to authentic aminochelin isolated by the methods of Page $\&$ von Tigerstrom (1988). Fractions containing aminochelin were pooled, reduced in volume to $25 \mathrm{ml}$ or less and extracted five times with butanol. The butanol extract was then evaporated to dryness under $\mathrm{N}_{2}$ and the resulting residue was suspended in $80 \%$ methanol and stored at $-20^{\circ} \mathrm{C}$.

The ethyl acetate fractions were pooled and reduced in volume to $200 \mathrm{ml}$. The concentrate was washed twice with an equal volume of $100 \mathrm{mM}$ sodium phosphate buffer ( $\mathrm{pH} \mathrm{7.0)}$, which removed azotochelin and 2,3-DHBA. Protochelin remained in the ethyl acetate layer and was concentrated and dissolved in $80 \%$ methanol. Purity was confirmed by TLC (Cornish \& Page, 1995) and the fraction was stored at $-20^{\circ} \mathrm{C}$.

The aqueous phase containing azotochelin and 2,3-DHBA was reduced to $200 \mathrm{ml}$, acidified to $\mathrm{pH} 1.8$ with $12 \mathrm{M} \mathrm{HCl}$, and extracted twice with an equal volume of ethyl acetate. The solvent was evaporated and the residue was resuspended in a minimum volume of $80 \%$ methanol for application to a $2.5 \mathrm{~cm} \times 30 \mathrm{~cm}$ Sephadex LH-20 (Pharmacia) column equilibrated with $80 \%$ methanol. Azotochelin and 2,3-DHBA were separated by elution with $80 \%$ methanol. Catecholates in fractions were detected by $A_{310}$ and identified by TLC (Cornish \& Page, 1995). Azotochelin-containing fractions were pooled, evaporated under $\mathrm{N}_{2}$, resuspended in a minimal volume of $80 \%$ methanol, and stored at $-20{ }^{\circ} \mathrm{C}$.

Molar iron-binding ratios and iron-affinity determination. Molar binding ratios of the three catecholate siderophores and $\mathrm{Fe}^{3+}$ were determined by the continuous-variation method of Job (Chaberek \& Martell, 1959). Each catecholate siderophore was mixed with $\mathrm{Fe}^{3+}$ (as ferric nitrate) in $100 \mathrm{mM}$ MOPS buffer ( $\mathrm{pH} 7.0)$ at various ratios and the absorbance of these mixtures was measured at $300-700 \mathrm{~nm}$ until each solution reached equilibrium. The ratio of siderophore to $\mathrm{Fe}^{3+}$ that gave the maximum absorbance represented the molar binding ratio. The wavelength of the maximum absorbance at the molar binding ratio was used in all further work.

The affinity of each siderophore for $\mathrm{Fe}^{3+}$ and $\mathrm{Fe}^{2+}$ (as ferrous sulfate), was determined by competition with EDTA as described by Reid et al. (1993). The iron-siderophore complex $(0.1 \mathrm{mM}$ final concentration) was allowed to form and equilibrate for $72 \mathrm{~h}$ before being mixed with $0.05-2.0 \mathrm{mM}$ (final concentration) EDTA and incubated for $96 \mathrm{~h}$ at room temperature. Conversely, solutions containing $0.05 \mathrm{mM}$ to $2.0 \mathrm{mM}$ iron-EDTA complex were incubated with $0.1 \mathrm{mM}$ siderophore for $96 \mathrm{~h}$. The concentration of the ironsiderophore complex in each reaction at equilibrium was determined spectrophotometrically by comparison to a standard curve. Protochelin was added to these assays in $80 \%$ methanol because of the low solubility of the uncomplexed ligand in aqueous solution, as described by Harris et al. (1979). Aminochelin and azotochelin stocks were dried under a $\mathrm{N}_{2}$ stream and dissolved in $100 \mathrm{mM}$ MOPS buffer ( $\mathrm{pH} 7 \cdot 0$ ) before use. All reactions $(250 \mu \mathrm{l}$ volume) were done in 96-well microtitre plates and absorbance was measured with a Biotek Instruments EL311 microplate reader, with a minimum of two duplicate series containing six replicates of each reaction mixture.

Cell-free extract preparation and enzyme activity. Strains UW and LM100 were grown under standard conditions in $200 \mathrm{ml}$ iron-limited or iron-sufficient $(75 \mu \mathrm{M}$ ferric citrate) medium. Cells were harvested by centrifugation $(4000 \mathrm{~g}, 10$ $\mathrm{min}$ ) and the cell pellet was washed with $50 \mathrm{mM}$ potassium phosphate buffer (pH 7.6) containing 2 mM DTT. Cells were resuspended in buffer and lysed in a French press as described by Page $\&$ von Tigerstrom (1982). The cell extract was cleared by centrifugation $(40000 \mathrm{~g}, 1 \mathrm{~h})$ and the resulting cell-free extract was stored at $-20^{\circ} \mathrm{C}$.

Catalase activity was determined by following the inhibition of $\mathrm{H}_{2} \mathrm{O}_{2}$-mediated reduction of dichromate $\mathrm{Cr}$ (VI) to chromic $\mathrm{Cr}$ (II) acetate (Sinha, 1972). One unit (U) of catalase activity was defined as the degradation of $1 \mu \mathrm{mol} \mathrm{H}_{2} \mathrm{O}_{2} \min ^{-1}$ ( $\mathrm{ml}$ enzyme $)^{-1}$. SOD activity was measured by its ability to inhibit the reduction of nitro blue tetrazolium $(\mathrm{NBT})$ by $\cdot \mathrm{O}_{2}^{-}$(Oberley \& Spitz, 1985). One unit of SOD activity was defined as the amount of protein required to inhibit the maximal rate of NBT reduction by $50 \%$, which was obtained graphically. Values reported are means calculated from at least duplicate assays in which the standard deviation was not greater than $10 \%$.

Catalase and SOD species were visualized after nondenaturing PAGE of cell-free extract protein. The proteins were separated in $7.5 \%$ acrylamide $(100 \mathrm{~cm} \times 80 \mathrm{~cm}$ Hoeffer mini-gel apparatus) under a $15-25 \mathrm{~mA}$ current. Catalase activity was demonstrated as described by Clare et al. (1984) except that the gel was soaked in $10 \mathrm{U}$ horseradish peroxidase $\mathrm{ml}^{-1}$ for $105 \mathrm{~min}$ and $5.0 \mathrm{mM} \mathrm{H} \mathrm{O}_{2}$ for $45 \mathrm{~min}$. SOD activity was located as described by Beauchamp \& Fridovich (1971). The iron-dependent SOD (Fe-SOD) was inhibited by soaking the gel in $5 \mathrm{mM} \mathrm{H}_{2} \mathrm{O}_{2}$ for 20 min before the normal SOD activity stain was applied (Allgood \& Perry, 1985).

Oxygen radical generation. The ability of ferric-siderophore complexes to withhold iron from the Fenton reaction was tested as follows. Siderophore from an $80 \%$ methanol stock was concentrated by evaporation under $\mathrm{N}_{2}$, resuspended in $60 \mathrm{mM}$ potassium phosphate buffer $(\mathrm{pH} 7.6)$ at $37^{\circ} \mathrm{C}$ and mixed with $10 \mathrm{mM}$ ferric nitrate in the appropriate molar ratio to obtain a ferric-siderophore that was $100 \%$ saturated with $\mathrm{Fe}^{3+}$. Ferric-siderophore complexes were allowed to form for at least $72 \mathrm{~h}$ before use. Iron released from a siderophore after its reduction to $\mathrm{Fe}^{2+}$ by $\cdot \mathrm{O}_{2}^{-}$was followed with ferrozine (Coffman et al., 1990), except that ferricsiderophore complexes containing a potential free $\mathrm{Fe}^{2+}$ concentration of 15 to $45 \mu \mathrm{M}$ were used. Each reaction contained $100 \mathrm{mU}$ xanthine oxidase $\mathrm{ml}^{-1} ; 500 \mathrm{U}$ catalase $\mathrm{ml}^{-1}$ or $30 \mathrm{U}$ SOD $\mathrm{ml}^{-1}$ was also added to some reactions. The molar absorption coefficient for the $\mathrm{Fe}^{2+}$-ferrozine complex of $27900 A_{562} \mathrm{~cm}^{-1} \mathrm{M}^{-1}$ (Stookey, 1970) was used to calculate the amount of $\mathrm{Fe}^{2+}$ released.

The detection of $\cdot \mathrm{OH}$ generation by the Fenton reaction was based on Coffman et al. (1990). Ferric-siderophore complexes were used which contained potential free $\mathrm{Fe}^{2+}$ concentrations of 5-30 $\mu \mathrm{M}$. Ferric-EDTA in the same concentration range was used as a positive control for $\cdot \mathrm{OH}$ generation. Xanthine oxidase was used at a final concentration of $100 \mathrm{mU} \mathrm{ml}^{-1}$ in reactions $(1.0 \mathrm{ml})$ containing $6 \mathrm{mM}$ potassium phosphate buffer $(\mathrm{pH} 7.6)$ and $4.5 \mathrm{mM}$ deoxyribose. Catalase $(500 \mathrm{U}$ $\left.\mathrm{ml}^{-1}\right)$ and SOD $\left(30 \mathrm{U} \mathrm{ml}^{-1}\right)$ were added to some reactions. Reactions were allowed to proceed for $15 \mathrm{~min}$ at room temperature and were stopped by the addition of $250 \mu \mathrm{l} 14.4 \%$ 
$(w / v)$ trichloroacetic acid. Deoxyribose that had reacted with - OH formed a coloured complex with the addition of $250 \mu \mathrm{l}$ $1 \%(\mathrm{w} / \mathrm{v})$ thiobarbituric acid in $0.1 \mathrm{M} \mathrm{NaOH}$. After heating for $15 \mathrm{~min}$ at $100^{\circ} \mathrm{C}$, the resulting $A_{532}$ values were expressed as a percentage of the ferric-EDTA control value.

\section{RESULTS}

\section{Oxidative stress and catecholate siderophore production}

Growth of wild-type A. vinelandii strain UW increased in iron-limited, nitrogen-free and nitrogen-sufficient medium as aeration increased until toxicity was reached at the highest aeration rate (Fig. 2a). Growth of $\mathrm{N}_{2}{ }^{-}$

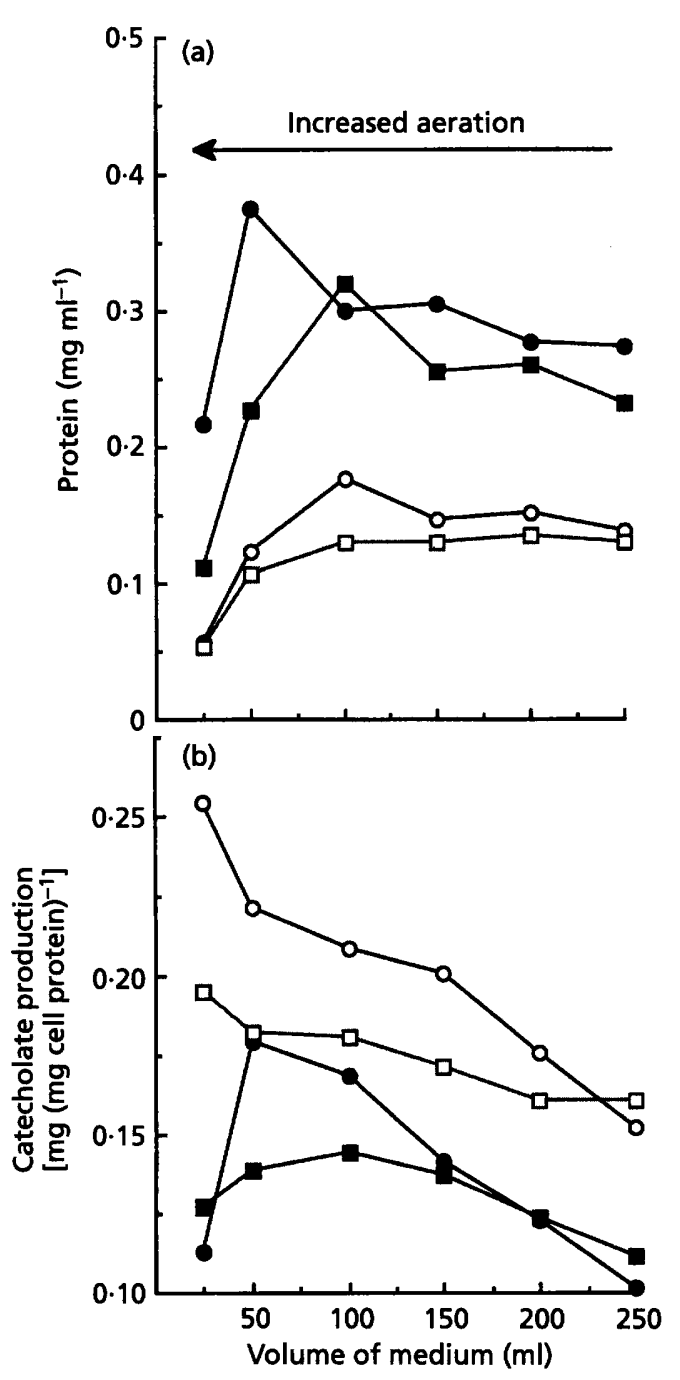

Fig. 2. (a) Effect of increased aeration on growth of $A$. vinelandii. Growth was estimated as cell protein after $22 \mathrm{~h}$ incubation of iron-limited nitrogen-sufficient medium with strain UW (O) or LM100 ( $\square$ ), and of iron-limited nitrogen-free medium with strain UW (O) or LM100 ( $\square$ ). (b) Effect of increased aeration on the formation of catecholate siderophores. Production of catecholates was measured in culture fluids from (a) (symbols are the same). fixing cells was adversely affected by iron limitation and increased aeration. Growth of strain LM100 in nitrogenfree medium was essentially the same as that of the wildtype, confirming that the mutation in FdI did not affect $\mathrm{N}_{2}$ fixation ability (Morgan et al., 1988). Growth of strain LM100 in nitrogen-sufficient medium was also like that of the wild-type, except at the highest aeration values (Fig. 2a). Iron-limited strains UW and LM100 demonstrated enhanced production of catecholate siderophores per cell protein as the aeration rate was increased (Fig. 2b). There was no apparent response of azotobactin production to increased aeration (data not shown), so this siderophore was not examined further in this study. Catecholate siderophore overproduction was most evident in $\mathrm{N}_{2}$-fixing cultures, which formed more catecholate than the corresponding cells grown with $\mathrm{NH}_{4}^{+}$, even at low aeration (Fig. $2 \mathrm{~b}$ ).

Culture supernatants were fractionated with ethyl acetate and sodium phosphate and the catecholates present in each fraction were identified by TLC and quantified by $A_{310}$ measurements. In both nitrogen-sufficient and nitrogen-free cultures of strain UW, aminochelin and azotochelin were present in a 1:0.9 ratio and accounted for about $95-97 \%$ of the catecholates present, regardless of aeration rate. Protochelin was barely detectable on TLC and accounted for only about $4-5 \%$ of total catecholates $(3-4 \mu \mathrm{M}$ in culture fluid). Similarly, in nitrogen-free cultures of strain LM100, aminochelin and azotochelin were present in a 1:0.8 ratio and accounted for about $92 \%$ of the catecholates present. Protochelin was again barely visible on TLC and accounted for about $6 \%$ of total catecholates, regardless of aeration rate. Similar abundance of the three catecholates were found in nitrogen-sufficient cultures of strain LM100 at low aeration, but protochelin became very definite on TLC and accounted for $17 \%$ of total catecholates $(17 \mu \mathrm{M}$ in culture fluid) as aeration was increased $(100 \mathrm{ml}$ per flask in Fig. 2a). At the next two higher aeration rates, which were growth inhibitory (Fig. 2a), protochelin declined to $13 \%$ and $6 \%$ of total catecholates.

\section{Affinity of catecholate siderophores for $\mathrm{Fe}^{3+}$ and $\mathrm{Fe}^{2+}$}

Assay of the molar iron-binding ratio showed that each purified siderophore bound either $\mathrm{Fe}^{3+}$ or $\mathrm{Fe}^{2+}$ in a ratio consistent with siderophore structure (Fig. 1): protochelin $1: 1$, azotochelin $3: 2$, and aminochelin $3: 1$. In all cases, the ferric- and ferrous-siderophore complexes exhibited broad spectral peaks; the $A_{\max }$ at equilibrium was at $490 \mathrm{~nm}$ with protochelin and at $570 \mathrm{~nm}$ with azotochelin. Only aminochelin demonstrated different $A_{\text {max }}$ wavelengths with $\mathrm{Fe}^{3+}(490 \mathrm{~nm})$ or $\mathrm{Fe}^{2+}(540 \mathrm{~nm})$. A stable complex with $\mathrm{Fe}^{3+}$ was formed most rapidly by protochelin (18 h), followed by aminochelin $(40 \mathrm{~h})$ and by azotochelin $(68 \mathrm{~h})$.

Using the determined molar binding ratios, the protondependent solubility constant for each siderophore with $\mathrm{Fe}^{3+}$ and $\mathrm{Fe}^{2+}$ was determined by competition with 
Table 1. Catecholate siderophore solubility constants with $\mathrm{Fe}^{3+}$ and $\mathrm{Fe}^{2+}$

\begin{tabular}{|c|c|c|c|c|c|}
\hline Reaction tested* & $\log _{10} K_{\mathrm{F}-\text { Sid }}$ & $\begin{array}{c}\text { Mean } \log _{10} \\
K_{\text {Fe-Sid }}\end{array}$ & Reaction tested ${ }^{*}$ & $\log _{10} K_{\mathrm{Fe}-\text { Sid }}$ & $\begin{array}{c}\text { Mean } \log _{10} \\
K_{\mathrm{Fe}-\text { Sid }}\end{array}$ \\
\hline $\mathrm{PcFe}^{3+}+$ EDTA & $24 \cdot 33$ & $24 \cdot 14$ & $\mathrm{PcFe}^{2+}+\mathrm{EDTA}$ & $13 \cdot 39$ & $13 \cdot 44$ \\
\hline $\mathrm{Pc}+\mathrm{Fe}^{3+}$ EDTA & $23 \cdot 48$ & & $\mathrm{Pc}+\mathrm{Fe}^{2+} \mathrm{EDTA}$ & $13 \cdot 85$ & \\
\hline $\mathrm{AzCFe}^{3+}+\mathrm{EDTA}$ & 53.55 & 53.47 & $\mathrm{AzCFe}^{2+}+\mathrm{EDTA}$ & 31.64 & $31 \cdot 67$ \\
\hline $\mathrm{AzC}+\mathrm{Fe}^{3+} \mathrm{EDTA}$ & $53 \cdot 42$ & & $\mathrm{AzC}+\mathrm{Fe}^{2+} \mathrm{EDTA}$ & $31 \cdot 75$ & \\
\hline $\mathrm{AmCFe}^{3+}+\mathrm{EDTA}$ & $30 \cdot 13$ & $30 \cdot 61$ & $\mathrm{AmCFe}^{2+}+\mathrm{EDTA}$ & $19 \cdot 19$ & $19 \cdot 28$ \\
\hline $\mathrm{AmC}+\mathrm{Fe}^{3+} \mathrm{EDTA}$ & $31 \cdot 25$ & & $\mathrm{AmC}+\mathrm{Fe}^{2+} \mathrm{EDTA}$ & $19 \cdot 51$ & \\
\hline
\end{tabular}

* Ligands: Pc, protochelin; AzC, azotochelin; AmC, aminochelin; all were used at appropriate molar binding ratios.

Table 2. Enzyme activities and electromorph relative mobilities from cells grown under iron-sufficient and iron-limited conditions

\begin{tabular}{|lccccc|}
\hline Strain & $\begin{array}{c}\text { Iron } \\
\text { content of } \\
\text { medium } \\
(\mu \mathrm{M})\end{array}$ & $\begin{array}{c}\text { SOD } \\
\text { electromorph } \\
\left(\boldsymbol{R}_{\mathrm{F}}\right)^{*}\end{array}$ & $\begin{array}{c}\text { SOD activity } \\
{[\mathbf{U}(\mathbf{m g}} \\
\left.\text { protein })^{-1}\right]\end{array}$ & $\begin{array}{c}\text { Catalase } \\
\text { electromorphs } \\
\left(\boldsymbol{R}_{\mathrm{F}}\right) \dagger\end{array}$ & $\begin{array}{c}\text { Catalase } \\
\text { activity [U (mg } \\
\left.\text { protein })^{-1}\right]\end{array}$ \\
\hline UW & 1 & 0.9 & 1.2 & $0.2 ; 0.5 ; 0.6$ & $38 \cdot 4$ \\
LM100 & 75 & 0.9 & $47 \cdot 0$ & $0.2 ; 0.5 ; 0.6$ & $38 \cdot 6$ \\
& 1 & 0.9 & 1.9 & $(0 \cdot 2) \neq ; 0.5 ; 0.6$ & $20 \cdot 2$ \\
& 75 & 0.9 & 18.4 & $(0 \cdot 2) \neq ; 0.5 ; 0.6$ & 18.5 \\
\hline
\end{tabular}

* $30 \mu \mathrm{g}$ cell-free extract protein was used for PAGE.

$\dagger 100 \mu \mathrm{g}$ cell-free extract protein was used for PAGE.

$\neq$ The electromorph at $R_{\mathrm{F}} 0.2$ was very faintly present.

EDTA (Table 1). Equilibrium was approached from either direction as the iron-siderophore complex was challenged with EDTA or the Fe-EDTA complex was challenged with siderophore. The values of $K_{\mathrm{Fe}-\mathrm{Sid}}$ were very close to each other, indicating that equilibrium could be approached from either direction. However, because of the different stoichiometry of each of the iron-binding reactions it was impossible to directly compare the solubility constants generated for each siderophore, since each value had different units. Thus it was only possible to directly compare the solubility constants that each siderophore had for $\mathrm{Fe}^{3+}$ or $\mathrm{Fe}^{2+}$ (Table 1). From this comparison it was clear that each siderophore had a higher affinity for $\mathrm{Fe}^{3+}$ than for $\mathrm{Fe}^{2+}$, which is one of the defining characteristics of a siderophore (Neilands 1981).

To directly compare the ability of different siderophores to bind $\mathrm{Fe}^{3+}$, the amount of free $\mathrm{Fe}^{3+}$ in a theoretical iron-siderophore system at $\mathrm{pH} 7.4$ was calculated, as described by Harris et al. (1979). Comparison of the free $\mathrm{Fe}^{3+}$ concentration was thus representative of the affinity that each siderophore had for $\mathrm{Fe}^{3+}$. This required the calculation of the proton-independent solubility coefficients for each siderophore using the proton-dependent solubility constants $(\mathrm{pH} 7 \cdot 0$ ) for each siderophore and $\mathrm{p} K_{\mathrm{a}}$ values from the model compound $N, N$-dimethyl-2,3-dihydroxybenzamide (Loomis \&
Raymond, 1991) as shown by Reid et al. (1993). From this value a proton-dependent solubility constant at pH 7.4 for each siderophore was calculated. This value was used to determine the free $\mathrm{Fe}^{3+}$ concentration in the hypothetical system. This value was expressed as $\mathrm{pFe}^{3+}$ $\left(-\log _{10}\left[\mathrm{Fe}^{3+}\right]\right)$; thus, the larger the $\mathrm{pFe}^{3+}$ value, the lower the concentration of free $\mathrm{Fe}^{3+}$ in solution, indicating that the siderophore has a higher affinity for iron. Protochelin was found to have a $\mathrm{pFe}^{3+}$ value of $27 \cdot 5$, which was approximately the same as that of ferrioxamine E (27.7) and about eight orders of magnitude lower than that of enterobactin $(35 \cdot 6)$. The $\mathrm{pFe}^{3+}$ value for azotochelin was calculated to be $23 \cdot 1$, which is slightly lower than that of aerobactin $(23.3)$ and one order of magnitude higher than that of aminochelin $(22 \cdot 0)$.

\section{Siderophores and oxygen radical formation}

The ability of each catecholate siderophore to retain iron in the presence of $\cdot \mathrm{O}_{2}^{-}$was examined. Only ferric-aminochelin released a significant amount of $\mathrm{Fe}^{2+}$ in the presence of $\cdot \mathrm{O}_{2}^{-}$. As the amount of potential free $\mathrm{Fe}^{2+}$ in the assay was increased from 5 to $50 \mu \mathrm{M}$, ferric-aminochelin continued to be the only siderophore that released $\mathrm{Fe}^{2+}$ (data not shown). Ferric-aminochelin released $\mathrm{Fe}^{2+}$ at a rate of $1.24 \mu \mathrm{M} \mathrm{Fe} \mathrm{min}^{2+}$ while ferric-protochelin and ferric-azotochelin released $\mathrm{Fe}^{2+}$ 
at rates of 0.07 and $0.13 \mu \mathrm{M} \mathrm{Fe}{ }^{2+} \min ^{-1}$, respectively. Addition of SOD to the iron-aminochelin reaction decreased the rate of $\mathrm{Fe}^{2+}$ release by $30 \%$ to $0.95 \mu \mathrm{M}$ $\mathrm{Fe}^{2+} \min ^{-1}$, indicating that $\mathrm{Fe}^{2+}$ release was $\cdot \mathrm{O}_{2}^{-}$ mediated, while the lack of the xanthine oxidase $\cdot \mathrm{O}_{2}^{-}$generating system prevented the release of $\mathrm{Fe}^{2+}$ altogether (data not shown).

The ability of each siderophore to participate in the formation of $\cdot \mathrm{OH}$ via the Fenton reaction was also studied. Ferric-aminochelin complexes were equal to the ferric-EDTA control in their ability to catalyse the formation of $\cdot \mathrm{OH}$. Ferric-protochelin and ferricazotochelin, on the other hand, generated $70 \%$ less - $\mathrm{OH}$ under identical conditions. Addition of catalase and SOD blocked $\cdot \mathrm{OH}$ formation in this assay.

\section{Activities of enzymes involved in oxygen stress management}

The activities of catalase and SOD were measured in cell-free extracts prepared from cells grown under standard iron-sufficient and iron-limited conditions (Table 2). The activity of SOD was notably decreased by iron limitation of the wild-type strain UW and mutant strain LM100. However, even in iron-sufficient medium, strain LM100 had only $39 \%$ of the SOD activity of strain UW. Similarly, catalase activity in strain LM100 was only $45-50 \%$ of that found in strain UW. Catalase activity was unaffected by iron limitation in both strains. The cell-free extracts from these cells were fractionated by non-denaturing PAGE and stained to identify the individual electromorphs of catalase and SOD (Table 2). Both strains had an identical single species of SOD, which was inactivated by $5 \% \mathrm{H}_{2} \mathrm{O}_{2}$, indicating that it was an Fe-SOD. Three catalase electromorphs were observed in strain UW, but strain LM100 produced significantly less of the catalase electromorph with an $R_{F}$ of $0 \cdot 2$.

Strain UW was much more resistant than strain LM100 to paraquat and the intracellular generation of $\cdot \mathrm{O}_{2}^{-}$ (Korbashi et al., 1986). In iron-sufficient medium, nitrogen-sufficient strain UW was inhibited completely by $40 \mu \mathrm{M}$ paraquat, whereas $\mathrm{N}_{2}$-fixing cells were inhibited by $30 \mu \mathrm{M}$ paraquat. In parallel iron-limited cultures, strain UW was more sensitive to paraquat $(20 \mu \mathrm{M}$ and $10 \mu \mathrm{M}$, respectively). However, strain LM100 was extremely sensitive to inhibition by paraquat, consistent with an inability to deal effectively with $\cdot \mathrm{O}_{2}^{-}$. Inhibition of growth of strain LM100 was complete at $5 \mu \mathrm{M}$ paraquat in iron-sufficient cells and at $3 \mu \mathrm{M}$ in ironlimited cells, regardless of the nitrogen source.

\section{DISCUSSION}

In order to bring about oxygen stress, A. vinelandii cells were grown under increasingly aerobic conditions in iron-limited medium. These cells had greatly decreased Fe-SOD activity as compared to iron-sufficient cells and thus $\cdot \mathrm{O}_{2}^{-}$was expected to be the main effector of oxidative stress. Decreased SOD activity could arise from the production of iron-deficient apoenzyme (Beyer
\& Fridovich, 1991) or could indicate that SOD transcription is activated by iron, as reported for $E$. coli and P. aeruginosa (Niederhoffer et al., 1990; Hassett et al., 1996). However, unlike the latter cells (Demple, 1996), A. vinelandii has no alternative $\mathrm{Mn}-\mathrm{SOD}$ to replace the missing Fe-SOD (this study; Jurtshuk et al., 1984). Unchecked $\cdot \mathrm{O}_{2}^{-}$can promote the Fenton reaction, but the formation of $\cdot \mathrm{OH}$ may be limited by the availability of iron and $\mathrm{H}_{2} \mathrm{O}_{2}$. Thus, the presence of undiminished catalase activity in iron-limited $A$. vinelandii strain UW may substantially decrease the impact of decreased SOD activity. Such is not the case in the isogenic $\mathrm{FdI}^{-}$strain LM100 (Morgan et al., 1988), which has decreased activity of both SOD and catalase even under ironsufficient growth conditions. This strain's decreased capacity to deal with $\cdot \mathrm{O}_{2}^{-}$stress also was shown by its extreme sensitivity to paraquat as compared to strain UW.

$\mathrm{N}_{2}$-fixing cells may be more sensitive to oxidative stress since $\cdot \mathrm{O}_{2}^{-}$can directly oxidize metal-containing enzymes or uncouple redox reactions, as well as participate in the Fenton reaction (Fridovich, 1986). When nitrogen limitation was coupled with iron limitation and high aeration, $A$. vinelandii overproduced catecholate siderophores. This response was not as pronounced in nitrogen-sufficient cultures, but there was still the trend towards greater catecholate production at higher aeration. Thus we questioned whether catecholate siderophores could play an additional role in limiting oxidative damage by sequestering iron.

Of particular interest was the tricatecholate protochelin, which was overproduced by oxygen-stressed strain LM100. The proton-independent solubility coefficient for protochelin was calculated to be very high $\left(10^{43 \cdot 9}\right)$. This value can be compared with that of other siderophores that bind $\mathrm{Fe}^{3+}$ in a $1: 1$ ratio since the units for the equilibrium coefficients are the same. Thus, protochelin has an affinity for $\mathrm{Fe}^{3+}$ that is about five orders of magnitude less than that of enterobactin $\left(10^{49}\right)$, but it is a superior chelator compared to ferrioxamine $B\left(10^{31}\right)$, pyoverdine $\mathrm{PaA}\left(10^{30 \cdot 8}\right)$, ferrichrome $\left(10^{29 \cdot 1}\right)$ and aerobactin $\left(10^{22 \cdot 5}\right.$ ) (Reid et al., 1993). Although both protochelin and enterobactin are tricatecholates, enterobactin has a much higher affinity for $\mathrm{Fe}^{3+}$ (Loomis \& Raymond, 1991). The most likely reason for this difference is that enterobactin contains a benzyl-serine triester ring that forms a rigid base for the attachment of the catechol moieties. This conformation makes it possible for enterobactin to easily align the catechols to form six coordinate bonds with $\mathrm{Fe}^{3+}$ (Hider, 1984). Protochelin, on the other hand, is a linear molecule that may form tetradentate coordination of $\mathrm{Fe}^{3+}$ quite easily, but a longer time may be needed to move the catechol on the putrescine arm into the final hexadentate coordination structure (Fig. 1).

Iron chelated by protochelin or azotochelin was not reduced by $\cdot \mathrm{O}_{2}^{-}$and limited $\cdot \mathrm{OH}$ formation by the Fenton reaction. Only iron chelated by aminochelin was unable to limit the Fenton reaction; it was readily reduced by $\cdot \mathrm{O}_{2}^{-}$and generated as much $\cdot \mathrm{OH}$ as the 
ferric-EDTA control. These results were consistent with the calculated proton-independent binding constants for the three siderophores. The affinity of protochelin for iron was higher than that of pyoverdin $\mathrm{PaA}$, a siderophore shown to prevent Fenton-mediated $\cdot \mathrm{OH}$ formation (Coffman et al., 1990). Ferric-azotochelin coordinated iron in a 3:2 ratio, bridging two iron molecules with three siderophore molecules in a manner similar to the interaction of rhodotorulic acid with $\mathrm{Fe}^{3+}$ (Carrano \& Raymond, 1978). Azotochelin had an affinity for $\mathrm{Fe}^{3+}$ that was at least four orders of magnitude less than that of protochelin, but it was still a better chelator of $\mathrm{Fe}^{3+}$ than aminochelin.

In a mixture of all three catecholates, as formed in ironlimited cultures of $A$. vinelandii, protochelin probably has the greatest effect in limiting the Fenton reaction. Protochelin is likely to form a stable iron complex first owing to its higher affinity for $\mathrm{Fe}^{3+}$ and faster reaction time. Previously, we questioned why wild-type $A$. vinelandii would normally form so little protochelin, when this tricatecholate was expected to be a superior iron chelator and siderophore (Cornish \& Page, 1995). However, a small amount (about 4-5 $\mu \mathrm{M}$ ) of protochelin may be sufficient if one of its major functions is to prevent iron-catalysed oxidative damage under the low$\mathrm{Fe}^{3+}$ growth conditions $(6 \mu \mathrm{M}$ or less) where catecholate siderophores are formed (Page \& von Tigerstrom, 1988). Thus the overproduction of protochelin by strain LM100 may well be an attempt to compensate for the decrease in catalase activity observed in iron-limited cells. This is another example of how Azotobacter spp. may use a chemical defence system when enzymic protection fails in iron-limited cells. It has been previously shown that Azotobacter salinestris, which has very low catalase activity, uses a catechol melanin to bind iron and minimize oxidative damage (Page \& Shivprasad, 1995; Shivprasad \& Page, 1989).

Collectively, these results suggest that catecholate biosynthesis in A. vinelandii may be under the dual control of iron repression (Cornish \& Page, 1995) and oxidative stress induction. It has been shown that $A$. vinelandii has a homologue of the Fur repressor (Mehrotra, 1997), so negative regulation by iron may follow the classic regulatory mechanism described by de Lorenzo et al. (1987). Recently it was proposed that the A. vinelandii FdI is part of a SoxRS-like system (Isas et al., 1995). It also has been proposed that FdI could be a redox sensor and it may bind to DNA directly to regulate gene expression (Thompson, 1991). Our results are certainly consistent with the hypothesis that $\mathrm{FdI}$ is involved in the $\cdot \mathrm{O}_{2}^{-}$stress response in $A$. vinelandii. Future studies on the regulation of the transcription of catecholate siderophore biosynthetic genes may help to resolve some of these issues.

\section{ACKNOWLEDGEMENTS}

We thank Barbara Burgess for the gift of strain LM100, and Robert Jordan and Miodrag Belosevic for their assistance with siderophore iron affinity determinations. Jennifer Snart and
Tara Dwinzel did preliminary work on this project with summer student support provided by the Alberta Heritage Foundation for Medical Research. This research is supported by an operating grant to W.J.P from the Natural Sciences and Engineering Research Council of Canada.

\section{REFERENCES}

Allgood, G. S. \& Perry, J. J. (1985). Oxygen defense systems in obligately thermophilic bacteria. Can J Microbiol 31, 1006-1010.

Barnum, D. W. (1977). Spectrophotometric determination of catechol, epinephrine, DOPA, dopamine and other aromatic vicdiols. Anal Chim Acta 89, 157-166.

Beauchamp, C. \& Fridovich, I. (1971). Superoxide dismutase: improved assays and an assay applicable to acrylamide gels. Anal Biochem 44, 276-287.

Beyer, W. F. \& Fridovich, I. (1991), In vivo competition between iron and manganese for occupancy of the active site region of the manganese-superoxide dismutase of Escherichia coli. J Biol Chem 266, 303-308.

Bishop, P. (1993). Three genetically distinct nitrogenase systems in Azotobacter vinelandii. In Iron Chelation in Plants and Soil Microorgansims, pp. 301-324. Edited by L. Barton \& B. C. Hemming. San Diego: Academic Press.

Carrano, C. J. \& Raymond, K. N. (1978). Coordination chemistry of microbial iron transport compounds. 10. Characterization of the complexes of rhodotorulic acid, a dihydroxamate siderophore. J Am Chem Soc 100, 5371-5374.

Chaberek, $S$ \& Martell, A. E. (1959). Organic Sequestering Agents. New York: Wiley.

Clare, D. A., Duong, M. N., Darr, D., Archibald, F. \& Fridovich, I. (1984). Effects of molecular oxygen on detection of superoxide radical with nitroblue tetrazolium and on activity stains for catalase. Anal Biochem 140, 532-537.

Coffman, T. J., Cox, C. D., Edeker, B. L. \& Britigan, B. E. (1990). Possible role of bacterial siderophores in inflammation. Iron bound to the Pseudomonas siderophore pyochelin can function as a hydroxyl radical catalyst. J Clin Invest 86, 1030-1037.

Cohen, G. (1994). Enzymatic/nonenzymatic sources of oxyradicals and regulation of antioxidant defenses. Ann N Y Acad Sci 738, 8-14.

Corbin, J. L. \& Bulen, W. A. (1969). The isolation and identification of 2,3-dihydroxybenzoic acid and 2-N,6-N-di(2,3-dihydroxybenzoyl)-L-lysine formed by iron-deficient Azotobacter vinelandii. Biochemistry 8, 757-762.

Cornish, A. S. \& Page, W. J. (1995). Production of the tricatecholate siderophore protochelin by Azotobacter vinelandii. BioMetals 8, 332-338.

Demple, B. (1996). Redox signaling and gene control in Escherichia coli soxRS oxidative stress regulon - a review. Gene 179, 53-57.

DiGuiseppi, J. \& Fridovich, I. (1984). The toxicity of molecular oxygen. Crit Rev Toxicol 12, 315-343.

Fridovich, I. (1986). Biological effects of the superoxide radical. Arch Biochem Biophys 247, 1-11.

Guerinot, M. L. (1994). Microbial iron transport. Annu Rev Microbiol 48, 743-772.

Harris, W. R., Carrani, C. J., Cooper, S. R., Sofen, S. R., Avdeef, A. E., McArdle, J. V. \& Raymond, K. N. (1979). Coordination chemistry of microbial iron transport compounds. 19 . Stability constants and electrochemical behavior of ferric enterobactin and model complexes. J Am Chem Soc 101, 6097-6104. 
Hassett, D. J., Sokol, P. A., Howell, M. L., Ma, J.-F., Schweitzer, H. T., Ochsner, U. \& Vasil, M. L. (1996). Ferric uptake regulator (Fur) mutants of Pseudomonas aeruginosa demonstrate defective siderophore-mediated iron uptake, altered aerobic growth, and decreased superoxide dismutase and catalase activities. J Bacteriol 178, 3996-4003.

Hider, R. C. (1984). Siderophore mediated absorption of iron. In Structure and Bonding: Siderophores from Microorganisms and Plants, vol. 58., pp. 26-87. Edited by M. J. Clarke, J. A. Ibers, D. M. P. Mingos, G. A. Palmer, P. J. Sadler \& R. J. P. Williams. Berlin: Springer.

Isas, J. M., Yannone, S. M. \& Burgess, B. K. (1995). Azotobacter vinelandii NADPH:ferredoxin reductase cloning, sequencing, and overexpression. J Biol Chem 36, 21258-21263.

Jurtshuk, P. \& Yang, T. (1980). Oxygen reactive hemoprotein components in bacterial respiratory systems. In Diversity of Bacterial Respiratory Systems, pp. 138-59. Editied by C. J. Knowles. Boca Raton, FL: CRC Press.

Jurtshuk, P., Jong-Kang, L. \& Moore, E. R. B. (1984). Comparative cytochrome oxidase and superoxide dismutase analyses on strains of Azotobacter vinelandii and other related free-living nitrogenfixing bacteria. Appl Environ Microbiol 47, 1185-1187.

Kolonay, J. F., Jr, Farhad, M., Gennis, R. B., Kaysser, T. M. \& Maier, R. J. (1994). Purification and characterization of the cytochrome bd complex from Azotobacter vinelandii: comparison to the complex from Escherichia coli. J Bacteriol 176, 4177-4181.

Korbashi, P., Kohen, R., Katzhendler, J. \& Chevion, M. (1986). Iron mediates paraquat toxicity in Escherichia coli. $J$ Biol Chem 261, 12472-12476.

Loomis, D. L. \& Raymond, K. N. (1991). Solution equilibria of enterobactin and metal-enterobactin complexes. Inorg Chem 30, 906-911.

de Lorenzo, V., Wee, S., Herrero, M. \& Neilands, J. B. (1987). Operator sequences of the aerobactin operon of plasmid ColVK30 binding the ferric uptake regulation (fur) repressor. J Bacteriol 169, 2624-2630.

Mehrotra, M. (1997). Role of iron in the regulation of phenylalanyl-tRNA synthetase activity in Azotobacter vinelandii. $\mathrm{PhD}$ thesis, University of Alberta.

Morgan, T. V., Lundell, D. J. \& Burgess, B. K. (1988). Azotobacter vinelandii ferredoxin. I. Cloning, sequencing, and mutant analysis. J Biol Chem 263, 1370-1375.
Neilands, J. B. (1981). Microbial iron compounds. Annu Rev Biochem 50, 715-731.

Niederhoffer, E. C., Naranjo, C. M., Bradley, K. L. \& Fee, J. A. (1990). Control of Escherichia coli superoxide dismutase (sodA and $s o d B$ ) genes by ferric uptake regulation (fur) locus. J Bacteriol 172, 1930-1938.

Oberley, L. W. \& Spitz, D. R. (1985). Nitroblue tetrazolium. In CRC Handbook of Methods for Oxygen Radical Research, pp. 217-220. Edited by R. A. Greenwald. Boca Raton, FL: CRC Press.

Page, W. J. \& Huyer, M. (1984). Derepression of the Azotobacter vinelandii siderophore system, using iron-containing minerals to limit iron repletion. J Bacteriol 158, 496-502.

Page, W. J. \& Shivprasad, S. (1995). Iron binding to Azotobacter salinestris melanin, iron mobilization and uptake mediated by siderophores. BioMetals 8, 59-64.

Page, W. J. \& von Tigerstrom, M. (1982). Iron- and molybdenumrepressible outer membrane proteins in competent Azotobacter vinelandii. J Bacteriol 151, 237-242.

Page, W. J. \& von Tigerstrom, M. (1988). Aminochelin, a catecholamine siderophore produced by Azotobacter vinelandii. J Gen Microbiol 134, 453-460.

Reid, R. T., Live, D. H., Faulkner, D. J. \& Butler, A. (1993). A siderophore from a marine bacterium with an exceptional ferric ion affinity constant. Nature 336, 455-458.

Shivprasad, S. \& Page, W. J. (1989). Catechol formation and melanization by $\mathrm{Na}^{+}$-dependent Azotobacter chroococcum: a protective mechanism for aeroadaptation? Appl Environ Microbiol 55, 1811-1817.

Sinha, A. K. (1972). Colormetric assay of catalase. Anal Biochem 47, 389-394.

Stookey, L. L. (1970). Ferrozine-a new spectrophotometric reagent for iron. Anal Chem 42, 779-781.

Thompson, A. J. (1991). Does ferredoxin I (Azotobacter) represent a novel class of DNA-binding proteins that regulate gene expression in response to cellular iron(II) ? FEBS Lett 285, 230-236.

Received 3 December 1997; revised 16 March 1998; accepted 26 March 1998. 